\title{
Research on Insurance Marketing under the Internet Financial Model
}

\author{
Junting $\mathrm{Pu}^{1,2,3} \quad$ Hongmei Zhang ${ }^{1,2,3}$ \\ ${ }^{1}$ Guizhou University of Finance and Economics, Institute of Finance \\ ${ }^{2}$ Guizhou Institution for Technology Innovation \& Entrepreneurship Investment \\ ${ }^{3}$ Guizhou Institute of Urban Economics and Development, Guiyang Guizhou
}

550025, China

\begin{abstract}
With the rapid development of Internet technology, modern society has entered an unprecedented stage of development. All industries have applied Internet technology to their own business processes, and the Internet finance model has developed into an overwhelming financial model. The rapid development of China's economy is inseparable from the contribution of the Internet finance model, but the Internet financial model has brought many influences to the insurance industry in China. From the perspective of Internet finance, this paper analyzes the present situation and risks of insurance network marketing in China, and puts forward corresponding development Suggestions.
\end{abstract}

\section{Keywords}

Internet finance; Insurance; Network marketing

\section{互联网金融模式下的保险营销研究}

\author{
蒲俊廷 ${ }^{1,2,3}$ 张红梅 ${ }^{1,2,3}$ \\ 贵州财经大学, ${ }^{1}$ 金融学院, ${ }^{2}$ 贵州科技创新创业投资研究院, \\ 3 贵州城镇经济与发展研究院，贵州贵阳 550025，中国
}

摘要：随着互联网技术的快速发展，现代社会进入了一个前所未有的发展阶段。各行各业都 将互联网技术应用于自己的业务流程之中，其中互联网金融模式更是发展成为一种势不可挡 的金融模式。我国经济的飞速发展离不开互联网金融模式的贡献，然而互联网金融模式也为 
我国保险行业带来了诸多的影响。本文从互联网金融的视角出发，分析了我国保险网络营销 的现状及面临的风险, 并提出相应的发展建议。

关键词: 互联网金融; 保险; 网络营销

\section{1. 引言}

互联网金融模式对我国的经济发 展来说是一把双刃剑, 既为我国的经济 发展带来了机遇, 同时也带来了一定的 风险。互联网金融模式是在网络技术飞 速发展的情况下而产生的, 而目前我国 的网络环境并不十分稳定, 且目前的网 络技术也不足以保证客户在网上办理 金融业务时的安全。在这种情形下，互 联网金融模式也为我国保险行业的发 展带来了风险隐患。要想让我国保险行 业健康稳定的发展, 就必须要防范可能 出现的风险并利用好互联网金融平台 的优势之处, 积极做好市场营销工作。

\section{2. 互联网金融模式保险营销的概述}

保险的网络营销是从美国开始的。 美国保险公司的网络营销在 90 年代获 得了飞速的发展并取得了惊人的成绩， 保险公司用户数量和投保金额都大幅 增加。现在美国几乎所有的保险公司都 已经借助网络平台进行保险营销, 到目 前为止, 美国部分险种网上交易额已经 达到 30\%到 50\%。同国外相比, 我国的 网络保险营销发展较晚, 2000 年前后, 国内保险公司才开始借助互联网平台 进行营销。从经营主体上看, 到 2016 年为止我国共有 117 家保险公司经营网 络保险营销业务, 比 2015 年 (110 家) 增长了 7 家, 我国目前已有 $75.97 \%$ 的保
险公司通过自建网站、与第三方平台合 作等不同经营模式开展了互联网保险 业务。从保费上看, 2016 年我国互联网 保险保费收入达到 2347 亿元, 较 2015 年 (2234 亿元) 增长了 113 亿元, 增幅 $5 \%$ 。相较于 2015 年 $160 \%$ 的增幅, 2016 年我国互联网保险的增长速度大幅度 下滑。互联网保费增幅的下降和渗透率 的下降, 主要跟保监会对理财型保险产 品监管收紧有关, 而互联网车险也因为 商车费改, 业务持续负增长, 导致互联 网财产险业务总体下滑, 影响了总体互 联网保费收入。

\section{3. 互联网金融模式保险营销面临的 风险及防范措施}

\section{1.保险网络营销缺乏稳定的基础}

保险和网络技术在我国家发展的 时间都不长久, 对保险业而言, 由于战 争、政治等因素，停滞了一段时间。虽 然网络技术与西方国家几乎同步发展, 但绝大多数直接照搬现有的技术和框 架, 不具备核心竞争力。想要保险业 互联网化, 企业就必须对两个行业有明 确的了解, 而且还要求企业做好充分的 准备应对可能面临的风险。

保险的网络营销不单单是建一个 官方网站进行宣传, 而且需要将保险的 业务流程也互联网化, 这就要求多个部 
门之间要相互配合, 同时工作习惯和组 织结构也要发生相应的调整, 甚至可能 会进行裁员。保险的网络营销必须以客 户的需求作为导向，除开产品的销售 外，还需要配套相应的服务，客户对企 业反馈的信息影响着其他客户对企业 的产品和服务态度的判断, 进而影响最 终的交易是否会达成。换句话说，如果 企业没有稳定的基础和足够的实力，保 险的网络销售可能会对保险机构产生 不良的影响。其次，保险业的核心流程 缺乏相应的技术支持，尚不能实现网络 化，比如核保。核保要求确定保单的内 容是否在承保条件范围以内, 当前各保 险机构的核保人都是企业精英，不仅掌 握保险业的知识, 且对保单涉及的领域 也十分清楚, 如汽车、身体健康等。核 保这个过程很难实现网络化, 但每笔业 务的流程之中必须有核保这一环节，可 想而知, 未来几年, 哪些公司能突破这 个难题, 便能在行业中占得有利位置。 最后, 互联网保险营销缺乏必要的监 督。在保险的网络营销业务流程中, 保 险机构和客户直接联系, 虽然避免了代 理商的参与, 但公司和客户并没有面对 面的接触, 这就可能会出现黑客入侵、 植入木马等风险。网上交易过程没有第 三方监管, 如果出现意外风险, 不可避 免的会出现企业有苦说不出, 客户抱怨 的情况。当然相关部门也熟知这个问题 的严重性，也相继制定出了一些法律条 款, 但仍然无法满足市场需求。

\section{2.保险网络销售定位不清晰}

保险行业的领头羊如中国平安、中
国人寿目前在互联网上的销售额占其 整体销售额的比例甚至小于 $10 \%$ 。产生 这种情况的原因有很多, 但我觉得主要 的原因是因为对保险网络营销的定位 不清晰。保险网络营销不光是利用互联 网对本公司的保险产品进行宣传, 而是 要形成一整套保险网络营销的标准化 流程, 这就需要将现实业务中的产品宣 传、保费收取、保险核保、承保等业务 流程全部实现网络化, 然而要实现这些 过程是需要经历相当长时间的设计、完 善和实践才能完成的。

\section{3.险种受到限制}

如今的保险业, 各类保险产品品种 的划分已经清晰明确了, 对于部分保险 险种, 客户已经比较了解, 再加上保险 条款并不复杂, 责任范围容易划分, 金 额低, 操作简单方便等因素使得这类保 险险种容易网络化, 如车险等。但由于 大多数保险险种投保过程复杂, 内容不 易理解, 理赔过程也比较复杂, 所以至 今还不适合借助互联网平台进行营销。

\section{4. 利益的重新分配产生的问题}

保险的网络营销最大的好处就是 极大节省了成本，公司和客户直接联 系, 免去了中间过程的花费。如果网络 营销可以规范化, 保险公司必然获益匪 浅, 但同时会对中介机构和各级保险代 理商的利益造成严重的威胁。他们也具 备自己的资源：客户信息。保险机构和 中间商都掌控着保险网络营销这条产 业链中的一些关键资源, 在互联网保险 营销这场战役中谁能获胜还不得而知。 


\section{5. 网络环境和相关法律法规不完善}

保险网络营销每笔业务涉及的金 额数量相比于其它网络购物的金额来 说是比较大的, 所以安全性成为了保险 网络营销的重中之重, 也是当下互联网 保险营销面临的最大威胁。首先, 最近 几年网络诈骗的丑闻不断被爆出, 使得 大多数客户在网上进行交易时更加小 心，尤其是中老年群体，有的甚至在亲 戚朋友的劝说下直接放弃了网上交易。

其次我国要加快推进网络实名制的实 施, 尽快推出每个网络交易者的网络身 份证, 这样才有助于网络的安全建设, 才能使保险的网络营销越走越远。

保险网络营销想要发展得更好必 须要出台相应的法律来对其进行规范, 保障它健康稳定的发展。网络保单的合 同都是以电子档的形式存在的, 客户需 要经过电子签名来使电子合同生效, 面 对这种情况, 国家在 2004 年出台了《中 华人民共和国电子签名法》来保障电子 合同的效力。但是互联网化的保险营销 过程可能会遇到很多法律擦边的情况, 甚至有些纠纷问题根本不在法律的界 定范围之内, 这就需要国家制定出完善 的法律法规。

\section{4. 加速推进互联网金融模式下保险 营销发展的建议}

\section{1.完善我国保险网络营销的监管}

加快完善相关法律法规。我国保险 网络营销的发展仍然处于初级阶段，尽 管迄今为止与网络保险有关的法律法
规已逐步建立起来, 但监管面还是非常 有限, 特别是与移动互联网保险相关的 规定还没有制定出来，所以，应该尽快 完善相关法律法规。继续完备保险网络 营销监管体系。现阶段中国保险网络营 销的有关法规十分有限, 很难对保险网 络营销市场进行约束，政府的监督显然 不够, 因此不光要政府建立相关法律法 规, 而且要建立起市场监管体系, 用来 填补政府监管的不足。首先要建立起保 险公司的内部风险控制机制, 防止因公 司内部的不恰当操作给客户带来经济 损失。二是积极发挥社会监督的作用, 让社会大众来共同监督互联网的保险 营销, 让消费者获得投诉的权利, 并开 通相应的投诉渠道。最后, 应该发挥行 业自律的作用, 由保险业协会组织各保 险公司签署并遵守行业自律规章制度。

\section{2. 提升网络交易的安全性}

预防网络的信息技术风险。互联网 信息技术风险波及的范围广泛，如果发 生, 会对保险网络营销带来极大的影 响, 所以要加大对此风险的防御力度。 人们可以通过以下的方法进行风险预 防：首先要按期检查和升级相关软件, 避免出现系统漏洞。其次要建立级别较 高的网络防火墙来防止黑客或者病毒 的侵入。三是要对客户的访问设立权 限, 运用身份证和密码进行认证。最后 要对公司重要的数据进行备份, 以防止 公司网络遭受攻击后数据丢失。

严防网络诈骗犯罪。网络的欺诈交 易和公司内部员工的违法操作对顾客 的合法权益造成了严重的损害，对此有 
关部门应定期对保险公司和网上保险 产品的交易进行检查，一旦发现违法犯 罪活动，有关部门应当给予严厉的惩 治。保障移动互联网保险交易的安全。 现在利用移动终端来进行保险网络交 易的人越来越多，如何保障其支付的安 全也成为了广大消费者考虑的首要问 题，因此必须加强移动终端进行保险网 络交易时的安全性。

\section{3. 有效提升保险网络营销服务质量}

把客户放在首位。保险网络营销的 竞争日趋激烈, 想通过低价来吸引客户 越来越不易，要想留住客户，保险公司 必须提升自己的服务质量, 创新与客户 沟通的形式，比如视频、电话等形式相 结合, 及时帮客户解答交易过程中的疑 难问题，了解每个消费者的不同需求， 给他们推荐适合他们各自的产品。强化 对保险网络营销人才的培养。当下保险 网络营销的局面对保险从业人员的工 作能力要求更高了, 员工不但要求熟知 保险的专业知识, 更是要求掌握保险网 络营销方面的知识。我们可以从以下几 点入手来培养保险网络营销的专业人 才: 一是加强员工的岗前培训, 二是保 险公司要加强与高校的合作力度, 联合 高校，利用高校资源来培养专业人才。 三是国外保险网络营销的发展更加成 熟，人才也更加丰富，因此我们可以招 揽国外优秀的保险专业人才。

\section{4.强化多方面的合作}

网络营销和传统营销相互配合。网 络营销和传统营销相互配合, 更加有助
于保险网络营销的发展。网络营销适合 一些简单型的保险产品, 对那些核保复 杂的保险产品, 我们可以利用互联网对 产品进行宣传, 如果客户想购买, 则转 为线下保险销售人员和客户进行沟通， 帮助其完成保险交易。与其他行业合 作。作为国内首家互联网保险公司的众 安保险之所以获得成功离不开它背后 金融、保险和互联网行业的相互合作, 这是以后保险行业发展的趋势所在。这 种跨界合作为保险网络营销带来的不 光是客户资源, 而且还有网络技术和电 商平台等。

\section{致谢}

本文由贵州财经大学 2017 年度保 险工作站科研项目资助，项目名称：互 联网金融模式下的保险营销研究。

\section{参考文献}

[1] 李文莲,夏健明. 基于 “大数据”的 商业模式创 新 $[\mathrm{J}]$. 企业管 理,2013,05(5):83-95.

[2] 白冬虎. 试论我国保险的网络营 销 [J]. 山西财经大学学 报,2011,33(2):37-39.

[3] 左小川. 浅析我国保险网络营销 的问题与对策 $[\mathrm{J}]$. 保险职业学院 学报,2012,26(5):50-51.

[4] 赵艳飞,徐斌. 基于互联网金融模 式下的保险营销研究 [J]. 黑龙江 科学, 2017,8(1):20-21.

[5] 王一方.互联网金融背景下保险的 网络营销策略 [J]. 改革与战略, 2017,33(7):75-77.

[6] 李峰. 互联网信息技术在保险营 销中的运用 $[\mathrm{D}]$.四川: 西南财经大 学,2013:1-48. 